\title{
BUILDING IT AMBIDEXTERITY IN PARADOXICAL TIMES: THE ROLE OF IT PROJECT AMBIDEXTERITY
}

\author{
Rogerio Kaneko \\ EAESP FGV \\ kanekor67@,outlook.com
}

\author{
Otavio Sanchez \\ EAESP FGV \\ otavio.sanchez@,fgv.br
}

\begin{abstract}
IT ambidexterity, the ability to simultaneously explore and exploit IT resources, is becoming increasingly important because it influences the organizational agility and helps organizations deal with growing levels of paradoxical tensions. In response to the opportunities and threats in the digital world, firms implement IT projects that face decision paradoxes which confront aspects such as control and autonomy, stability and change, and short-and long-term view. Extant theories describe how certain IT components contribute to IT ambidexterity; however, the literature is silent on how effectively managing these paradoxes in IT projects influences IT ambidexterity. To address this gap, this paper proposes a new construct, IT project ambidexterity, the ability to ambidextrously deal with paradoxes in IT projects, evaluate its influence on IT ambidexterity with a sample of 132 Brazilian IT executives, and found a relevant effect of IT project ambidexterity on IT ambidexterity.
\end{abstract}

\section{Introduction}

Business publications have a wealth of articles arguing the world is becoming more volatile, uncertain, complex, and ambiguous (a.k.a. VUCA) [1-5]. In consequence of this volatility, organizations seek the agility to respond more effectively to the VUCA world's opportunities and threats by using information technologies (IT) [6, 7].

The multiplicity of consequent IT projects [7-9] is subjected to several paradoxical tensions. Paradox is defined as a "persistent contradiction between interdependent elements" [10]. Ambidexterity refers to the firm's ability to simultaneously exploit and explore with their resources and practices [11] and it is an organizational quality that perhaps can be considered the most studied of the paradoxes [10]. Lee et al. leveraged this organizational concept to propose IT ambidexterity (ITA) as "the ability of firms to simultaneously explore new IT resources and practices
(IT exploration) as well as exploit their current IT resources and practices (IT exploitation)" [12].

Extant literature describes the influence of specific IT components on ITA [13]; however, it is silent about if a simultaneous focus on exploration and exploitation when dealing with IT projects' paradoxes could favor ITA. This is a crucial blind spot because IT projects have many embedded paradoxes [14] and represent an important means to materialize IT-supported changes.

To address this research question, we propose the IT project ambidexterity (ITPA) construct, defined as the ability of firms to simultaneously emphasize the interdependent exploitation and exploration elements of persistent contradictions in IT projects. We also propose a nomological model to evaluate ITPA's influence on ITA. We collected data from 132 Brazilian IT executives during June 2020 and analyzed the relationships with PLS-SEM. Results show that that ITPA positively and significantly influences ITA.

This study's contribution to the IS field is threefold. First, it highlights the paradox theory as a promising lens to investigate the phenomena of embedded paradoxical decisions into IT projects, which is the rule in a digital transformation context. Second, it conceptualizes an important construct, ITPA, that helps understand the nature of the paradoxes faced by IT executives and how they influence ITA. Third, it measures the influence of ITPA on ITA, thus illuminating a new key relationship. Finally, for IT practitioners, this study can help improve real-world IT project's effectiveness by increasing awareness about their paradoxes and thus help accelerate their firm's ITA evolution.

The following sections in this document are devoted to theory review, research model proposal, data collection, results analysis, and conclusions.

\section{Theoretical Background}

This section reviews the ambidexterity concept and the paradox theory's current state in the literature. 


\subsection{Paradox Theory}

As the environmental dynamism increases, organizations are challenged with more intense tensions between competing demands and objectives [15]. Smith and Lewis [16] informed these tensions could be categorized as dilemmas, dialectics, or paradoxes. Dilemmas are "competing choices, each with advantages and disadvantages" while dialectics are "contradictory elements (thesis and antithesis) resolved through integration (synthesis), which, overtime will confront new opposition" [16]. Dilemmas can be illustrated by a decision of make or buy a software and a dialectics example can be the synthesis of the tension between volume and unit cost of a 3D printer production scenario. On the other hand, paradox is defined as "a persistent contradiction between interdependent elements" [10]. This concept can be exemplified by the tension between speed and fuel efficiency where, in general, higher speed hurts fuel efficiency and vice versa. It is possible, however, to imagine scenarios where technology can alter this logic and enable an ambidextrous alternative where speed and fuel efficiency can be simultaneously pursued (e.g., through aerodynamic improvements).

In a recent systematic literature review, Schad et al. [10] followed Smith and Lewis [16] and grouped the paradoxes into four categories by their type of tensions as per table 1 below:

Table 1. Paradoxes categories [10]

\begin{tabular}{|c|c|c|}
\hline Category & $\begin{array}{l}\text { Tension } \\
\text { Nature }\end{array}$ & Typical Paradoxes \\
\hline Learning & $\begin{array}{l}\text { evolutionary } \\
\text { or growth }\end{array}$ & $\begin{array}{l}\text { old and new, stability and } \\
\text { change, exploration, and } \\
\text { exploitation, short- and } \\
\text { long-term focus }\end{array}$ \\
\hline Organizing & $\begin{array}{l}\text { competing } \\
\text { designs and } \\
\text { processes }\end{array}$ & $\begin{array}{l}\text { alignment and flexibility, } \\
\text { control and autonomy, } \\
\text { differentiation, and } \\
\text { integration }\end{array}$ \\
\hline Belonging & $\begin{array}{l}\text { competing } \\
\text { identities }\end{array}$ & $\begin{array}{l}\text { individual and collective } \\
\text { affiliations, cooperate and } \\
\text { compete }\end{array}$ \\
\hline Performing & $\begin{array}{l}\text { goals } \\
\text { tensions }\end{array}$ & $\begin{array}{l}\text { internal and external } \\
\text { demands, multiple } \\
\text { stakeholders' conflicting } \\
\text { objectives }\end{array}$ \\
\hline
\end{tabular}

Learning paradoxes relate to the evolution or growth tensions. It encompasses the ambiguity of further exploiting existing strengths or breaking up with the status quo and exploring new approaches. This exploration and exploitation tension is one of the most studied paradoxes and manifests on other related tensions like stability and change or short- and longterm focus. Organizing paradoxes derive from structuring and processes options associated with differentiation and integration choices [17]. It includes, for example, the firm's organizational structure and governance processes. The core of these tensions has alignment and control in one pole and flexibility and autonomy on the other pole. Belonging paradoxes, on the other hand, has to do with the affiliation conflicts an individual experiments in a particular organization, including values and beliefs conflicts [17], or with the cooperate and compete tension in a multi-organization setting. Finally, performing paradoxes surface more at the individual level when someone's action is asked to fulfil multiple conflicting demands or objectives [10]. According to Jarzabkowski et al. [17], the organizing paradoxes take place at the macro (organizational) level, while the performing paradoxes occur at the micro (individual) level and the belonging paradoxes at the meso (group) level. Learning paradoxes are multi-level and impact organizations, groups, and individuals.

The typical paradox response strategies are summarized in table 2 below:

\begin{tabular}{|c|c|c|}
\hline $\begin{array}{l}\text { Response } \\
\text { Approach }\end{array}$ & General Idea & Strategies \\
\hline Acceptance & $\begin{array}{l}\text { "embrace" and } \\
\text { "accept } \\
\text { paradoxes as } \\
\text { persistent and } \\
\text { unsolvable } \\
\text { puzzles" }\end{array}$ & $\begin{array}{l}\text { Proactive: e.g., } \\
\text { ambidexterity } \\
\text { Passive: e.g., laissez- } \\
\text { faire leadership }\end{array}$ \\
\hline Resolution & $\begin{array}{l}\text { "finding a means } \\
\text { of meeting } \\
\text { competing } \\
\text { demands or } \\
\text { considering } \\
\text { divergent ideas } \\
\text { simultaneously" }\end{array}$ & $\begin{array}{l}\text { Spatial Separation: } \\
\text { e.g., separate } \\
\text { innovation lab } \\
\text { Temporal Separation: } \\
\text { e.g., punctuated } \\
\text { equilibrium } \\
\text { Synthesis: e.g., glocal } \\
\text { (for global vs. local) }\end{array}$ \\
\hline
\end{tabular}

The passive acceptance strategy takes place when the organization gives up trying to deal with the paradoxes and accept whatever fate or destiny brings. In contrast with this unassertive option, the proactive acceptance strategy is a more innovative approach but requires more energy and the ability to truly open the tensions for discussion and even change the organization's culture for long term success. The resolution approach, on the other hand, seeks a reasonable way to cope with the competing demands. Spatial separation can be seen, for example, when an innovation department (e.g., R\&D) is formed and physically segregated (e.g., different room, floor, building) from daily operations to mutually shield one group's values, objectives, and resources from another. Temporal separation can be observed with companies that display a punctuated equilibrium, long periods of resources and assets exploitation broken by short 
periods of intense innovation, possibly triggered by an external threat or a new executive decision. Synthesis happens when a new solution emerges and attenuates the pre-existing tension, at least temporarily. An example is the "think global act local" as a synthesis for the local versus global perspectives.

Scholars from multiple fields, including strategy and organization, have adopted the paradox perspective [15], and the number of articles using this theoretical lens increased significantly from 1990 to 2014 (25 years) [18]. A simplified bibliometric update based on the Scopus Database, showed the trend continued post2014 and, in fact, gained momentum in the last three years. In 2014, 552 articles had the term "paradox" in the keyword field while in 2019 this number increased to 789 .

This theory's success is so visible that Cunha and Putnam [18] recently warned about the risk of scholars becoming overconfident on this dominant explanation and losing the ability to critically envision alternative approaches. In response to this alert, Schad et al. [15] highlighted the role of two paradoxical forces, centripetal and centrifugal, on theory development. They also offered advice on how to continue evolving the paradox theory, through the centrifugal force, while preserving the core, that forges the common language necessary to allow theory dissemination and adoption, through the centripetal force.

We recognize the importance of remaining open to better explanations but concur with Schad et al. [15] regarding the high potential of the paradox theoretical lens to study various phenomena in the current dynamic and ambiguous world.

\subsection{Ambidexterity}

For many decades, ambidexterity has been a topic of interest for various fields, including organizational science and information systems. The concept goes back to March's [19] foundational article that discussed the relationship between exploration and exploitation in organizational learning. Exploration has to do with flexibility, risk-taking, innovation, and preparing the organization for the future, while exploitation is linked to efficiency, standardization, production and a focus on short-term success [19]. An exclusive focus on exploitation limits the organization's ability to evolve, thus threatening its future; on the other hand, an exploration only mindset puts the organization's current competitiveness and even survival at risk. Organizational ambidexterity is defined as the firm's ability to simultaneously emphasize exploration and exploitation. Achieving ambidexterity at the organizational level enhances the firm's performance and competitiveness [20] and is crucial for its long-term survival [21] and success [22].

Jarvenpaa and Wernick [23] studied four open innovation networks and identified industry-driven research had a tendency for incremental innovation, that connects with the exploitation idea, while academic research units were looking more towards disruptive innovations [24], aligned with the exploration concept. When looking from the innovation perspective, ambidexterity is the ability to pursue incremental and disruptive innovations simultaneously.

Previous studies identified three broader strategies to achieve ambidexterity. In the sequential approach, the entire organization alternates long periods of exploitation with shorter periods of intense exploration (i.e. punctuated equilibrium) [25]. This is an older strategy more useful in stable and slower moving environments, thus less viable in the current world of intense dynamism and rivalry. On top of this limitations, O'Reilly III and Tushman [26] went further to question if this approach could generate ambidexterity since exploration and exploitation would not happen at the same moment. In the contextual approach, the individuals are encouraged and supported to decide when to emphasize exploitation or exploration, based on their judgement of the situation. This is apparently a more flexible approach, but it requires the right culture and processes to be viable. At the same time, this approach lacks the power to generate a large-scale radical ambidexterity because of the decision power granted to the individual level [26]. The structural approach requires the creation of a dedicated unit for innovation (e.g., R\&D centers, Digital Innovation Labs, etc), that operates independently and have their own people, competence, incentives, etc. An overarching vision and strong leadership are also key elements [26] in this approach, and its main deficiency is a difficulty to transition innovated ideas or products from the exploration unit to the operational units. Table 3 summarizes these approach's main characteristics.

Table 3. Forms of ambidexterity. Adapted from O'Reilly III and Tushman [26] and Holotiuk and Beimborn [27]

\begin{tabular}{|c|c|c|c|}
\hline Item & Structural & Contextual & Sequential \\
\hline Reference & $\begin{array}{l}\text { O'Reilly III } \\
\text { and } \\
\text { Tushman } \\
\text { [11] }\end{array}$ & $\begin{array}{l}\text { Gibson and } \\
\text { Birkinshaw } \\
{[28]}\end{array}$ & $\begin{array}{l}\text { Tushman } \\
\text { and } \\
\text { Romanelli } \\
\text { [25] }\end{array}$ \\
\hline Level & Organization & Individual & Organization \\
\hline $\begin{array}{l}\text { General } \\
\text { Idea }\end{array}$ & $\begin{array}{l}\text { Exploitation } \\
\text { and } \\
\text { exploration } \\
\text { occur in } \\
\text { separate } \\
\text { and } \\
\text { specialized } \\
\text { units }\end{array}$ & $\begin{array}{l}\text { Individual } \\
\text { decides to } \\
\text { emphasize } \\
\text { exploitation } \\
\text { or } \\
\text { exploration } \\
\text { depending }\end{array}$ & $\begin{array}{l}\text { Entire } \\
\text { organization } \\
\text { alternates } \\
\text { from } \\
\text { exploitation } \\
\text { to } \\
\text { exploration } \\
\text { and then }\end{array}$ \\
\hline
\end{tabular}




\begin{tabular}{l|l|l|l}
\hline & & $\begin{array}{l}\text { on the } \\
\text { situation }\end{array}$ & $\begin{array}{l}\text { back to } \\
\text { exploitation }\end{array}$ \\
\hline $\begin{array}{l}\text { Dedicated } \\
\text { Unit for } \\
\text { Innovation }\end{array}$ & $\begin{array}{l}\text { Yes } \\
\text { (With } \\
\text { permanent } \\
\text { staffing) }\end{array}$ & No & No \\
\hline
\end{tabular}

Building on the existing studies, Holotiuk and Beimborn [27] proposed a fourth approach, temporal ambidexterity, when evaluating how digital innovation labs (DIL) connect exploration and exploitation for digital innovation. Per this concept, the operational units keep a focus on exploitation, and a separate dedicated unit, a DIL, emphasizes exploration. Individuals from the operating units are temporarily assigned to the DIL, thus creating an ambidextrous work collaboration environment that, after some time, allows the development of an ambidextrous view as both groups have to work through the paradoxical tensions together. After the assignment period, individuals go back to their operating units taking new perspectives with them and embracing the on-going support and exploitation of the digital artifacts they helped create. Holotiuk and Beimborn [27] concluded that "temporal ambidexterity is particularly suited for digital innovation".

Ambidexterity is not confined to the organizational level. In the information systems field, IT ambidexterity (ITA) is defined as "the ability of firms to simultaneously explore new IT resources and practices (IT exploration) as well as exploit their current IT resources and practices (IT exploitation)" [12]. Previous studies already informed that ITA positively influences organizational agility $[12,29,30]$ and described the influence of certain IT components on ITA [13], however, the amount of ITA research is still limited. In its most fruitful full year to date, 2017, only five articles in the Scopus database had the term "IT ambidexterity" in the title, abstract or keyword fields. This number increased on 2020, reaching eight articles by the end of October 2020, what could possibly indicate an increased interest for this theme.

When discussing how to measure ambidexterity, Cao et al. [20] untangled the concept into its balance dimension (BD) and combined dimension (CD). BD evaluates the relative balance between exploratory and exploitative activities and is defined as the inverse of the absolute difference between these two elements. BD thus considers that ambidexterity is maximum if these two elements have the same intensity. This approach might be counter-intuitive at times as, for example, it considers ambidexterity is high when exploration and exploitation levels are both extremely low. CD, on the other hand, assesses the intensity in simultaneously performing exploration and exploitation and is defined as the product of these elements. CD will be low if exploration and exploitation levels are both low, and high if these two elements' levels are also high. For this behavior, $\mathrm{CD}$ is the most commonly used ambidexterity measurement approach [31] and is also adopted in this study.

\section{IT Project Ambidexterity Conceptualization}

IT projects are exposed to paradoxes, and, with an ambidextrous response, more innovative and superior approaches can be pursued [14]. Simply avoiding the tension, through temporal or spatial separation, or emphasizing only one side of the paradoxes, tend to lead to sub-optimal solutions, especially in the current dynamic environment.

Having a construct to measure the organization's ambidexterity in IT projects can enable superior approaches so we searched the literature for such construct. We used the Scopus database and looked for articles with the terms "IT project" and "paradox", "IT project" and "ambidexterity", and "project ambidexterity" in the title, abstract and keyword fields. A total of 19 articles were retrieved and revised but none of them presented the desired construct. As we didn't find the construct, we decided to propose a new one following the procedure of MacKenzie et al. [32].

The starting point is the construct conceptualization that describes what it is intended to represent and how it differs from other similar constructs [32]. Leveraging the paradox theory and the ITA literature we define our new construct, IT project ambidexterity (ITPA), as "the ability of firms to simultaneously emphasize the interdependent exploitation and exploration elements of persistent contradictions in IT projects".

Per this definition, ITPA applies to the organizational level and captures the ability of a firm to simultaneously focus the two sides of the paradoxes in IT projects, namely: exploitation and exploration. Exploitation looks for efficiency in the short-term and involves the increased integration and reuse of existing resources and capacities. Exploration, on the other hand, connects with the idea of preparing the organization for the longer-term through the identification and adoption of new capacities and resources that create some sort of advantage.

ITPA differs from ITA on its focus and locus. ITPA sees the paradoxical tensions only within IT projects while ITA contemplates the regular daily IT operations as well. ITA is concentrated on the IT function, but ITPA takes into consideration, for example, how non-IT stakeholders influence IT projects.

In the measurement development we started by identifying the paradoxes that take place inside IT projects [32]. We assembled a preliminary list based on 
the literature [14] and the experience of two IT executives. We found 21 paradoxes, composed by two poles, the exploration and exploitation elements of each paradox. This list was then submitted to a panel of five experts with extensive practical IT project experience, who evaluated the understanding and meaning of the phrases, their relevance and prevalence. After implementing small adjustments recommended by the panel, this version was pre-tested with a group of 50 Brazilian IT executives. General feedback was that the ITPA indicators were hard to read and thus a deeper revision was conducted and a second list with 16 shortphrased paradoxes was obtained. These paradoxes were then regrouped into the four main paradox categories identified in the literature: learning, organizing, belonging, and performing [10]. This new list was subsequently submitted to two senior IT executives with the PMP certification and years of experience as a project management officer. The items in this new list were deemed to have good readability and content validity while also being relevant and prevalent. Afterwards, these list's elements were used as the survey items.

Once the key paradoxes were identified by the above process, we formally specified the measurement model as a second-order construct with a reflexive relationship [32] to four first-order constructs, which represented ITPA in the four main paradox categories. Each of the four first-order constructs is measured by four indicators which were obtained by multiplying the two elements of four paradoxes that were independently surveyed. This approach was referred by Cao et al. [20] as the combined dimension (CD) and, according to Koryak et al. [31], this is the most common way of measuring ambidexterity. Since each paradox element was measured with a likert-7 scale, a given paradox CD can assume values from 1 to 49 .

We performed the traditional scale assessment procedures like factorial analysis and reliability check. From this point, we moved to the nomological validation [32], which is discussed in the following sections.

\section{Research Model}

ITA involves a dual focus on the exploration and exploitation paradox, so we argue that improving the ability to embrace paradoxes on all the IT domain aspects would possibly contribute to explain ITA. Dealing with technology has many facets [13, 33], among them the implementation of IT projects, a common means to deliver IT-supported changes. We then propose the nomological network presented in Figure 1 below:

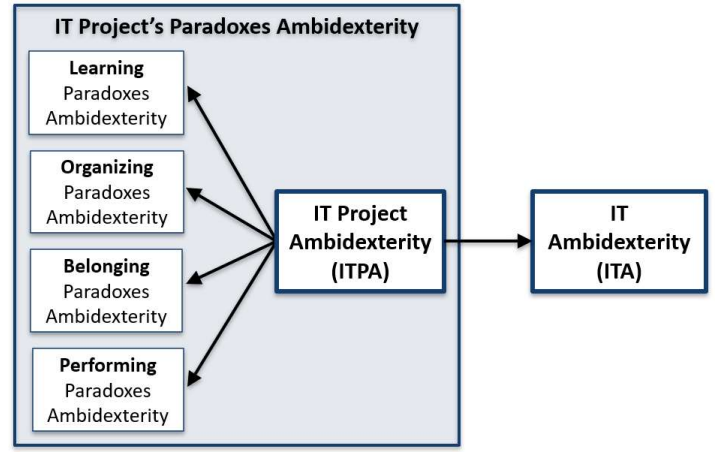

Figure 1. Nomological network employed

\section{Item operationalization}

An electronic survey instrument was developed to collect the perspectives of Brazilian IT executives on the constructs presented in table 4 below:

Table 4. Survey instrument constructs

\begin{tabular}{|c|c|c|c|}
\hline Construct & Operationalization & $\begin{array}{c}\text { Number of } \\
\text { Items }\end{array}$ & References \\
\hline $\begin{array}{l}\text { IT Project } \\
\text { Ambidexterity } \\
\text { (ITPA) }\end{array}$ & $\begin{array}{l}\text { 2nd order } \\
\text { reflexive latent }\end{array}$ & 16 & \multirow{5}{*}{$\begin{array}{l}\text { concepts, } \\
\text { classification } \\
\text { and definitions } \\
\text { following } \\
\text { Gregory et al. } \\
\text { [14]; all items } \\
\text { proposed by } \\
\text { authors }\end{array}$} \\
\hline $\begin{array}{l}\text { Learning } \\
\text { Paradoxes } \\
\text { Ambidext. }\end{array}$ & $\begin{array}{l}\text { first order 7-point } \\
\text { Likert scale }\end{array}$ & 4 & \\
\hline $\begin{array}{l}\text { Organizing } \\
\text { Paradoxes } \\
\text { Ambidext. }\end{array}$ & $\begin{array}{l}\text { first order 7-point } \\
\text { Likert scale }\end{array}$ & 4 & \\
\hline $\begin{array}{l}\text { Belonging } \\
\text { Paradoxes } \\
\text { Ambidext. }\end{array}$ & $\begin{array}{l}\text { first order 7-point } \\
\text { Likert scale }\end{array}$ & 4 & \\
\hline $\begin{array}{l}\text { Performing } \\
\text { Paradoxes } \\
\text { Ambidext. }\end{array}$ & $\begin{array}{l}\text { first order 7-point } \\
\text { Likert scale }\end{array}$ & 4 & \\
\hline $\begin{array}{l}\text { IT } \\
\text { Ambidexterity } \\
\text { (ITA) }\end{array}$ & $\begin{array}{c}\text { first order 7-point } \\
\text { Likert scale }\end{array}$ & 6 & $\begin{array}{l}\text { Based on Lee } \\
\text { et al. [12] }\end{array}$ \\
\hline
\end{tabular}

ITPA is the new second-order construct defined as "the ability of firms to simultaneously emphasize the interdependent exploitation and exploration elements of persistent contradictions in IT projects". It is measured by 16 items, four for each of its four first order constructs as previously discussed in section three.

We use the ITA construct as proposed by Lee et al. [12], which is defined as "the ability of firms to simultaneously explore new IT resources and practices (IT exploration) as well as exploit their current IT resources and practices (IT exploitation)", as discussed in section 2.2. The associated measurement scale has six items, three for IT exploration and another three for IT exploitation. We adopted the original ITA scale in full after its translation from English to Portuguese. To 
ensure translation validity, we forwarded the translation proposal to a panel of five Portuguese native speakers with more than 20 years of IT service in multinational firms, and extensive use of English for daily communication. The joint feedback offered some improvements that were incorporated into the final survey.

In addition to the ITA and ITPA measurement items, two attention check questions were added to enable quality validations [34] and other variables were included to control for firm's strategic orientation [35], environmental dynamism [33], size [2], age, industry [36] and the respondent's role and seniority.

The survey instrument was then pre-tested with a group of 50 Brazilian IT executives in May 2020 and only few wording adjustments were deemed necessary.

\section{Data Collection}

The refined electronic survey instrument was then published in Jun 2020 and remained open for almost two weeks. We issued an article on LinkedIn presenting the research objectives, inviting IT executives to respond the survey and asking them to publicize the invitation in their professional networks, thus creating a snowballing effect. We then forwarded this article to hundreds of IT executives through personalized LinkedIn direct messages. The invitation was also posted on WhatsApp groups containing IT executives that are also MSc or Ph.D. candidates. To increase participation, we committed to donating ten Reais, approximately two US dollars, for each valid and complete response to Instituto Ayrton Senna (IAS), an NGO managed by the Formula 1 Brazilian racer family and dedicated to improving education in Brazil.

The survey was closed on Jun 20th, 2020. In total, 247 respondents took the survey, but only 201 responded to all questions. Abandon rate was $18.6 \%$ (46 respondents). Another 42 responses (17\%) had to be discarded due to attention check failures, so the valid response count was 159. As an additional precaution, we restricted the response set to IT Managers or IT Project Managers and above, having at least 5 years of IT experience, resulting in a total of 132 valid responses. This precaution was considered important because junior professionals might not have enough experience to recognize the paradoxes we are intending to identify. We tested against minimum sample size by means of $\mathrm{G}^{*}$ Power 3 software [37] which showed the required sample size to detect a medium (0.15) effect with a $1 \%$ $\alpha$ error probability and a $95 \%$ power is 123 observations.

\section{Results}

\subsection{Descriptive Statistics}

We assessed the respondent's profile and found that over $90 \%$ of them self-declared having more than ten years of IT experience and occupying a leadership role as CIO or IT Manager/Director/Vice-President and alike. This level of seniority was obtained after the removal of 27 responses provided by less experienced professionals in the believe that higher ranks tend to be more capable to identify the paradoxes involved in the study.

Firm industry profile in the sample shows more service $(71.2 \%)$ than industrial $(19.7 \%)$ firms. A little over $80 \%$ of the firms have 20 years or more of presence in Brazil, and $70 \%$ fall into the large company criteria, according to BNDES [2]. Likewise, when assessing size through the IT user count, 56\% have more than 500 IT users in Brazil, and another $21 \%$ have between 100 and 500 users. Operational excellence is the prevailing strategic orientation, with $42 \%$ of the industrial firms and $39 \%$ of the service firms. Environmental dynamism is more intense for service firms (18\% on the 4 th quartile) than for their industrial counterparts $(\sim 4 \%$ on the 4th quartile).

There is a good balance on the origin of capital criteria, which qualifies between Brazilian (47\%) and non-Brazilian (51\%) firms, and on the stock listing criteria, that shows $51 \%$ of the firms are publicly traded, and $44 \%$ are privately held.

\subsection{Measurement Model Evaluation}

The systematic evaluation of a PLS-SEM model is a two-step process that begins with the measurement model evaluation and ends with the structural model evaluation [38]. The first step focuses on the measurement model reliability and validity criteria. We started by evaluating the indicator's reliability expressed by the measurement item's outer loadings. There is a general agreement that outer loadings should be 0.7 or higher, but there is also a recognition that, in practice, lower loadings are common, especially on newly created scales [38, 39]. Except for one of the belonging construct items (CD-B2) that had a 0.654 outer loading, all items exceeded the 0.7 mark.

We also evaluated the measurement model discriminant validity through the item's cross-loadings presented in table 5 below. As desired, the item's loadings were higher on the constructs they intend to measure as per the values highlighted in bold. 
Table 5. Item's cross-loadings

\begin{tabular}{l|c|c|c|c|c|c}
\hline Item I Construct & Learning & Organizing & Belonging & Performing & ITPA & ITA \\
\hline CD-L1 & $\mathbf{0 . 8 6 5}$ & 0.491 & 0.555 & 0.486 & 0.705 & 0.422 \\
\hline CD-L2 & $\mathbf{0 . 7 1 3}$ & 0.493 & 0.496 & 0.467 & 0.642 & 0.439 \\
\hline CD-L3 & $\mathbf{0 . 7 3 2}$ & 0.390 & 0.556 & 0.499 & 0.651 & 0.378 \\
\hline CD-L4 & $\mathbf{0 . 7 4 2}$ & 0.383 & 0.332 & 0.382 & 0.535 & 0.322 \\
\hline CD-O1 & 0.434 & $\mathbf{0 . 7 6 7}$ & 0.440 & 0.421 & 0.586 & 0.256 \\
\hline CD-O2 & 0.470 & $\mathbf{0 . 7 9 2}$ & 0.454 & 0.381 & 0.609 & 0.423 \\
\hline CD-O3 & 0.375 & $\mathbf{0 . 7 8 7}$ & 0.507 & 0.362 & 0.576 & 0.387 \\
\hline CD-O4 & 0.528 & $\mathbf{0 . 8 0 3}$ & 0.557 & 0.455 & 0.678 & 0.454 \\
\hline CD-B1 & 0.412 & 0.473 & $\mathbf{0 . 7 8 5}$ & 0.556 & 0.664 & 0.381 \\
\hline CD-B2 & 0.345 & 0.341 & $\mathbf{0 . 6 5 4}$ & 0.414 & 0.534 & 0.320 \\
\hline CD-B3 & 0.594 & 0.549 & $\mathbf{0 . 8 4 3}$ & 0.599 & 0.773 & 0.444 \\
\hline CD-B4 & 0.612 & 0.552 & $\mathbf{0 . 8 2 4}$ & 0.624 & 0.770 & 0.430 \\
\hline CD-P1 & 0.461 & 0.412 & 0.539 & $\mathbf{0 . 8 1 1}$ & 0.657 & 0.352 \\
\hline CD-P2 & 0.500 & 0.457 & 0.632 & $\mathbf{0 . 8 8 8}$ & 0.732 & 0.339 \\
\hline CD-P3 & 0.507 & 0.397 & 0.595 & $\mathbf{0 . 8 4 9}$ & 0.689 & 0.397 \\
\hline CD-P4 & 0.567 & 0.472 & 0.631 & $\mathbf{0 . 8 3 1}$ & 0.742 & 0.367 \\
\hline Learning (Latent Var) & 0.977 & 0.570 & 0.660 & 0.608 & $\mathbf{0 . 8 4 4}$ & 0.532 \\
\hline Organizing (Latent Var) & 0.550 & 0.944 & 0.591 & 0.503 & $\mathbf{0 . 7 7 0}$ & 0.474 \\
\hline Belonging (Latent Var) & 0.655 & 0.619 & 0.993 & 0.704 & $\mathbf{0 . 8 9 1}$ & 0.516 \\
\hline Performing (Latent Var) & 0.590 & 0.497 & 0.698 & 0.972 & $\mathbf{0 . 8 2 8}$ & 0.416 \\
\hline IT Ambidexterity & 0.514 & 0.486 & 0.509 & 0.430 & 0.581 & $\mathbf{1 . 0 0 0}$ \\
\hline
\end{tabular}

We then analyzed the construct's internal consistency reliability, and validity [38]. Internal consistency was assessed through Cronbach's alpha and composite reliability, the former representing a lower bound and the latter an upper bound for reliability [38]. The lowest coefficient was 0.762 so all the constructs presented values above 0.7 , the commonly accepted threshold [38]. The convergent validity was assessed through Average Variance Extracted (AVE) and all the constructs surpassed the 0.5 generally requested mark [38], being 0.586 the lowest coefficient. The next step was to evaluate the construct's discriminant validity which was adequate since the values in the diagonal are the highest for the respective lines and columns. Table 6 below summarizes this discussion.

Table 6. Overall reliabilities, AVE, means, standard deviations, and correlations.

Note: $\mathrm{CA}=$ Cronbach's Alpha, $\mathrm{CR}=\mathrm{Composite}$ Reliability, $\mathrm{AVE}=$ Average Variance Extracted, bold values along the diagonal

\begin{tabular}{|c|c|c|c|c|c|c|c|c|c|}
\hline & $\mathrm{CA}$ & $\mathrm{CR}$ & AVE & 1 & 2 & $2 \mathrm{~A}$ & $2 \mathrm{~B}$ & $2 \mathrm{C}$ & $2 \mathrm{D}$ \\
\hline 1. ITA & 1.000 & 1.000 & 1.000 & 1.000 & & & & & \\
\hline 2. ITPA & 0.854 & 0.901 & 0.696 & 0.581 & 0.834 & & & & \\
\hline 2A. Learning & 0.762 & 0.849 & 0.586 & 0.514 & 0.834 & 0.765 & & & \\
\hline 2B. Organizing & 0.796 & 0.867 & 0.620 & 0.486 & 0.780 & 0.578 & 0.788 & & \\
\hline 2C. Belonging & 0.784 & 0.860 & 0.608 & 0.509 & 0.889 & 0.644 & 0.624 & 0.780 & \\
\hline 2D. Performing & 0.866 & 0.909 & 0.714 & 0.430 & 0.836 & 0.604 & 0.516 & 0.711 & 0.845 \\
\hline
\end{tabular}

The procedures above contemplate the ITPA scale validation of a construct proposal [32]. The new measurement model was assessed for reliability, discriminant, and convergent validity.

\subsection{Structural Model Evaluation}

The second step of a systematic PLS-SEM model evaluation is the structural model evaluation [38]. We estimated the structural model via PLS-SEM algorithm and significances with 5000 bootstrapping procedure using the default SmartPLS 3. 
The research model was also evaluated for the industrial and service firms' sub-samples. We started by executing the three steps of the measurement invariance of composite models (MICOM) procedure $[40,41]$. We checked configural invariance (step 1), compositional invariance (step 2), and the equality of composite mean values and variances (step 3) and, once partial measurement invariance was confirmed, we moved to PLS-MGA.

Table 7 contains a summary of the path coefficients showing a strong positive and significant effect of ITPA on ITA, indicating the nomological validity of the construct. For group analysis, the results we found show that full sample and service firms have similar effects. We statistically compared the path coefficients for the service and industry firms and, although the coefficient difference is high, the results were non-significant $(0.357, \mathrm{p}=0.077)$, possibly due to industry's small size $(\mathrm{n}=26)$. We further analyzed the intergroup variance difference and found service firms have a higher variance than industrial firms $(0.07$, $\mathrm{p}<0.05)$.

Table 7. Path coefficients for industrial and service firms. Note: $(n s): p \geq 0.05 ;(*): p<0.05 ;(* *)$ : $p$ $<0.01 ;\left(^{* * *}\right): p<0.001$.

\begin{tabular}{l|c|c|c|c}
\hline & $\begin{array}{c}\text { Full } \\
\text { Sample } \\
(\mathrm{N}=132)\end{array}$ & $\begin{array}{c}\text { Industrial } \\
\text { Firms } \\
(\mathrm{N}=26)\end{array}$ & $\begin{array}{c}\text { Service } \\
\text { Firms } \\
(\mathrm{N}=94)\end{array}$ & $\begin{array}{c}\text { Industrial } \\
\text { Versus } \\
\text { Service }\end{array}$ \\
\hline ITPA $\rightarrow$ & 0.834 & 0.903 & 0.822 & 0.082 \\
Learning & $\left(^{* * *}\right)$ & $\left(^{* * *}\right)$ & $\left(^{* * *}\right)$ & $(\mathrm{ns})$ \\
\hline ITPA $\rightarrow$ & 0.780 & 0.842 & 0.776 & 0.066 \\
Organizing & $\left(^{* * *}\right)$ & $\left(^{* * *}\right)$ & $\left(^{* * *}\right)$ & $(\mathrm{ns})$ \\
\hline ITPA $\rightarrow$ & 0.889 & 0.899 & 0.883 & 0.016 \\
Belonging & $\left(^{* * *}\right)$ & $\left(^{* * *}\right)$ & $\left(^{* * *}\right)$ & $(\mathrm{ns})$ \\
\hline ITPA $\rightarrow$ & 0.836 & 0.770 & 0.838 & -0.067 \\
Performing & $\left(^{* * *}\right)$ & $\left(^{* * *}\right)$ & $\left(^{* * *}\right)$ & $(\mathrm{ns})$ \\
\hline ITPA $\rightarrow$ & 0.581 & 0.266 & 0.623 & -0.357 \\
ITA & $\left(^{* * *}\right)$ & $(\mathrm{ns})$ & $\left(^{* * *}\right)$ & $(\mathrm{ns})$ \\
\hline
\end{tabular}

Similarly, table 8 summarizes the variance explained $\left(\mathrm{R}^{2}\right)$ results by firm industry type. It shows ITPA explains a substantial amount of all its firstorder constructs' variance. ITPA also explains a moderate amount of ITA variance for service firms and a low amount for industrial firms.

\section{Table 8. Variance explained $\left(\mathbf{R}^{2}\right)$ for industrial} and service firms

\begin{tabular}{l|c|c|c}
\hline & $\begin{array}{c}\text { Full } \\
\text { Sample } \\
(\mathrm{N}=132)\end{array}$ & $\begin{array}{c}\text { Industrial } \\
\text { Firms } \\
(\mathrm{N}=26)\end{array}$ & $\begin{array}{c}\text { Service } \\
\text { Firms } \\
(\mathrm{N}=94)\end{array}$ \\
\hline Learning & $69.6 \%$ & $81.6 \%$ & $67.5 \%$ \\
\hline Organizing & $60.9 \%$ & $70.9 \%$ & $60.2 \%$ \\
\hline Belonging & $79.0 \%$ & $80.8 \%$ & $77.9 \%$ \\
\hline Performing & $69.9 \%$ & $59.3 \%$ & $70.2 \%$ \\
\hline ITA & $33.8 \%$ & $7.1 \%$ & $38.8 \%$ \\
\hline
\end{tabular}

We then evaluated the model's out-of-sample predictive power, examining Stone-Geisser's $\mathrm{Q}^{2}$ value [38] by performing the blindfolding procedure, choosing distances between five and ten. We concluded the model has a good out-of-sample predictive power as all the $\mathrm{Q}^{2}$ values are positive (smaller $\mathrm{Q}^{2}$ was 0.314).

\section{Discussion}

We successfully proposed a new construct, IT project ambidexterity (ITPA), with four reflexive firstorder constructs, matching key paradox categories found in the literature [16]. After carefully developing the scale, it has been empirically tested and showed significant, good properties, and well-balanced weights, thus confirming the quality of the proposed configuration.

As the business environment gets increasingly dynamic, organizations seek agility through technology and their IT projects become more embedded with paradoxical tensions [14]. These tensions are ingrained in the decisions addressed in the projects following four categories: learning, organizing, belonging, and performing. The more ambidextrously these paradoxes are treated, the higher the IT ambidexterity. Accordingly, our study demonstrated that ITPA has a positive influence on ITA.

We also found that ITPA influence on ITA is stronger in service than in industrial firms and the variance is higher for the service sector. A possible explanation for this difference refers to the potential higher environmental dynamism of the service sector. Industrial firms have a heavier asset base (e.g., plant equipment) and operate in a more cadenced environment when compared to the service firms (e.g., media and entertainment). We believe there are less paradoxical tensions instilled in industrial firms' IT projects and this characteristic reduces ITPA enactment on ITA. Further confirmation of this envisioned explanation might be pursued in future studies.

Like any other study, this investigation has limitations. First, it is important to recognize data 
collection took place under the Covid-19 pandemic social distancing restrictions. It is our perception that IT professionals have been dealing with a high workload at data collection time. We relied on attention check questions to increase the rigor and discard responses with any indication of reduced attention levels while responding the questionnaire.

It is also important to recognize that data was collected through a snowballing approach. We minimized the possible associated bias by actively pushing the survey to IT executives on groups outside the authors' relationship network.

For practitioners, our study can be leveraged by IT executives as a ruler to measure ITPA at a more foundational level, the learning, organizing, belonging, and performing dimensions of an IT project. This ability would facilitate the identification of specific areas with lower ambidexterity levels when dealing with projects and thus inform the IT executives about necessary course corrections to expedite the IT ambidexterity capacity development.

By offering a new construct, this study prepares the foundation for future investigations. It would be interesting to assess the ITPA influence on other constructs like the IT application orchestration capability, that ultimately influences firm performance [42]. While ITPA is conceptualized at the project level, some paradoxical tensions are expected to take place at the program level or at the program to project interface [14]. Analyzing these possible differences may open new avenues for research, including the expansion of the ITPA concept to these additional levels. The current research model could also be enriched through the addition of moderating factors. For example, we speculate that using a high level of contractor staffing in IT projects may reduce the influence of ITPA on ITA, meaning third party consultants that come and go according to the project lifecycle might leave a lower contribution to the overall IT function ambidexterity construction. Another possible moderator would be the project orientation level of a firm. We suspect the ITPA influence on ITA may be lower on highly projectoriented firms because this more mature methodological approach could potentially help reduce some of the paradoxical tensions in IT projects.

\section{Conclusion}

Organizations are increasingly exposed to paradoxes, and our study discusses how the ability to deal with them in IT projects influence the construction of an IT function capable of simultaneously emphasizing exploration and exploitation characteristics.
We conceptualized and tested a new construct, ITPA, and found it has a positive and significant influence on ITA. This is a crucial relationship because previous studies already demonstrated ITA favors organizational agility and business performance. In essence, we shed additional light on how to achieve these almost universal strategic imperatives.

We hope this study encourages other researchers to leverage the paradox theory in their investigations as the current environment is indeed full of paradoxical tensions. We also aspire to see the ITPA construct being used to help advance the information systems field and contributing to real-life digital transformation journeys.

\section{References}

1. Bennett, N. and G.J. Lemoine, What a difference a word makes: Understanding threats to performance in a VUCA world. Business Horizons, 2014. 57(3): p. 311317.

2. BNDES. Company size classification (Classificação do Porte de Empresa). 2020; Available from: https://www.bndes.gov.br/wps/portal/site/home/financi amento/guia/porte-de-empresa.

3. Millar, C., O. Groth, and J.F. Mahon, Management Innovation in a VUCA World: Challenges and Recommendations. California Management Review, 2018. 61(1): p. 5-14.

4. Seow, P.S., G. Pan, and G. Koh, Examining an experiential learning approach to prepare students for the volatile, uncertain, complex and ambiguous (VUCA) work environment. International Journal of Management Education, 2019. 17(1): p. 62-76.

5. Thoren, K. and M. Vendel, Backcasting as a strategic management tool for meeting VUCA challenges. Journal of Strategy and Management, 2019. 12(2): p. 298-312.

6. Nwankpa, J.K. and Y. Roumani. IT capability and digital transformation: A firm performance perspective. in 2016 International Conference on Information Systems, ICIS 2016. 2016.

7. Rossmann, A. Digital maturity: Conceptualization and measurement model. in International Conference on Information Systems 2018, ICIS 2018. 2018.

8. Kane, G.C., et al., Aligning the Organization for Its Digital Future. MIT Sloan Management Review and Deloitte University Press, 2016(Summer).

9. Warner, K.S.R. and M. Wäger, Building dynamic capabilities for digital transformation: An ongoing process of strategic renewal. Long Range Planning, 2019. 52(3): p. 326-349.

10. Schad, J., et al., Paradox Research in Management Science: Looking Back to Move Forward. Academy of Management Annals, 2016. 10(1): p. 5-64.

11. O'Reilly III, C.A. and M.L. Tushman, Ambidexterity as a dynamic capability: Resolving the innovator's dilemma. Research in Organizational Behavior, 2008. 28: p. 185-206. 
12. Lee, O.-K., et al., How Does IT Ambidexterity Impact Organizational Agility? Information Systems Research, 2015. 26(2): p. 398-417.

13. Nwankpa, J.K. and P. Datta, Balancing exploration and exploitation of IT resources: the influence of Digital Business Intensity on perceived organizational performance. European Journal of Information Systems, 2017. 26(5): p. 469-488.

14. Gregory, R.W., et al., Paradoxes and the Nature of Ambidexterity in IT Transformation Programs. Information Systems Research, 2015. 26(1): p. 57-80.

15. Schad, J., M.W. Lewis, and W.K. Smith, Quo vadis, paradox? Centripetal and centrifugal forces in theory development. Strategic Organization, 2019. 17(1): p. 107-119.

16. Smith, W. and M. Lewis, Toward a theory of paradox: A dynamic equilibrium model of organizing. Academy of Management Review, 2011.36(2): p. 381-403.

17. Jarzabkowski, P., J.K. Lê, and A.H. Van de Ven, Responding to competing strategic demands: How organizing, belonging, and performing paradoxes coevolve. Strategic Organization, 2013. 11(3): p. 245280.

18. Cunha, M.P.E. and L.L. Putnam, Paradox theory and the paradox of success. Strategic Organization, 2019. 17(1): p. $95-106$

19. March, J.G., Exploration and exploitation in organizational learning. Organization Science, 1991. 2(1): p. 71-87.

20. Cao, Q., E. Gedajlovic, and H. Zhang, Unpacking organizational ambidexterity: Dimensions, contingencies, and synergistic effects. Organization Science, 2009. 20(4): p. 781-796.

21. Levinthal, D.A. and J.G. March, The myopia of learning. Strategic Management Journal, 1993. 14(2 S): p. 95-112.

22. Raisch, S. and J. Birkinshaw, Organizational ambidexterity: Antecedents, outcomes, and moderators. Journal of Management, 2008. 34(3): p. 375-409.

23. Jarvenpaa, S.L. and A. Wernick, Paradoxical tensions in open innovation networks. European Journal of Innovation Management, 2011. 14(4): p. 521-548.

24. Christensen, C.M., et al., Disruptive Innovation: An Intellectual History and Directions for Future Research. Journal of Management Studies, 2018. 55(7): p. 10431078.

25. Tushman, M.L. and E. Romanelli, ORGANIZATIONAL EVOLUTION: A METAMORPHOSIS MODEL OF CONVERGENCE AND REORIENTATION. Research in Organizational Behavior, 1985. 7: p. 171.

26. O'Reilly III, C.A. and M.L. Tushman, Organizational ambidexterity: Past, present, and future. Academy of Management Perspectives, 2013. 27(4): p. 324-338.

27. Holotiuk, F. and D. Beimborn, Temporal Ambidexterity: How Digital Innovation Labs Connect Exploration and Exploitation for Digital Innovation, in ICIS 2019, AIS, Editor. 2019: Munich, Germany.

28. Gibson, C.B. and J. Birkinshaw, The antecedents, consequences, and mediating role of organizational ambidexterity. Academy of Management Journal, 2004. 47(2): p. 209-226.
29. Brinkhues, R.A., et al. IT ambidexterity, organizational agility and information management capability: $A$ Brazilian case. in 25th Americas Conference on Information Systems, AMCIS 2019. 2019.

30. Zhou, J., et al., Understanding employee competence, operational IS alignment, and organizational agility An ambidexterity perspective. Information \& Management, 2018. 55(6): p. 695-708.

31. Koryak, O., et al., Disentangling the antecedents of ambidexterity: Exploration and exploitation. Research Policy, 2018. 47(2): p. 413-427.

32. MacKenzie, S.B., P.M. Podsakoff, and N.P. Podsakoff, Construct measurement and validation procedures in MIS and behavioral research: Integrating new and existing techniques. MIS Quarterly: Management Information Systems, 2011. 35(2): p. 293-334.

33. Chen, Y., et al., IT capability and organizational performance: the roles of business process agility and environmental factors. European Journal of Information Systems, 2017. 23(3): p. 326-342.

34. Abbey, J.D. and M.G. Meloy, Attention by design: Using attention checks to detect inattentive respondents and improve data quality. Journal of Operations Management, 2017. 53-56: p. 63-70.

35. Tallon, P.P., A Process-Oriented Perspective on the Alignment of Information Technology and Business Strategy. Journal of Management Information Systems, 2007. 24(3): p. 227-268.

36. Nations, U. International Standard Industrial Classification of All Economic Activities (ISIC), Rev.4. 2008; Available from: https://unstats.un.org/unsd/publication/seriesm/seriesm 4rev4e.pdf.

37. Faul, F., et al., G*Power 3: A flexible statistical power analysis program for the social, behavioral, and biomedical sciences. Behavior Research Methods, 2007. 39(2): p. 175-191.

38. Hair, J.F., et al., A primer on partial least squares structural equation modeling (PLS-SEM). 2nd edition ed. 2017, Thousand Oaks, CA: SAGE.

39. Hulland, J., Use of partial least squares (PLS) in strategic management research: A review of four recent studies. Strategic Management Journal, 1999. 20(2): p. 195-204.

40. Henseler, J., C.M. Ringle, and M. Sarstedt, Testing measurement invariance of composites using partial least squares. International Marketing Review, 2016. 33(3): p. 405-431.

41. Hair, J.F., et al., Advanced Issues in Partial Least Squares Structural Equation Modeling (PLS-SEM), . 2nd edition ed. 2018, Thousand Oaks, CA: SAGE.

42. Queiroz, M., et al., The role of IT application orchestration capability in improving agility and performance. The Journal of Strategic Information Systems, 2018. 27(1): p. 4-21. 